\title{
Efficacy of tiotropium/olodaterol on lung volume, exercise capacity, and physical activity
}

This article was published in the following Dove Press journal: International Journal of COPD

\author{
Masakazu Ichinose \\ Yoshiaki Minakata ${ }^{2}$ \\ Takashi Motegi ${ }^{3}$ \\ Jun Ueki ${ }^{4}$ \\ Yasuhiro Gon ${ }^{5}$ \\ Tetsuo Seki ${ }^{6}$ \\ Tatsuhiko Anzai ${ }^{7}$ \\ Shuhei Nakamura ${ }^{6}$ \\ Kazuto Hirata ${ }^{8}$
}

'Department of Respiratory Medicine, Tohoku University Graduate School of Medicine, Sendai, ${ }^{2}$ Department of Respiratory Medicine, National Hospital Organization Wakayama Hospital, Wakayama, ${ }^{3}$ Department of Pulmonary Medicine and Oncology, Graduate School of Medicine, Nippon Medical School, Tokyo, ${ }^{4}$ Clinical Research Unit of Respiratory Pathophysiology, Juntendo University Graduate School of Health Care and Nursing, Chiba, ${ }^{5}$ Division of Respiratory Medicine, Department of Internal Medicine, Nihon University School of Medicine, 'Medical Division, Nippon Boehringer Ingelheim Co., Ltd, ${ }^{7}$ Clinical Information Division Data Science Center, Statistics Analysis Department I, EPS Corporation, Tokyo, ${ }^{8}$ Osaka City University, Osaka, Japan
Correspondence: Masakazu Ichinose Department of Respiratory Medicine, Tohoku University Graduate School of Medicine, I-I Seiryo-machi, Aoba-ku, Sendai $980-8574$, Japan

Tel +8I 0227178534

Fax +8I 0227178549

Email ichinose@rm.med.tohoku.ac
Purpose: This study evaluated the efficacy of tiotropium/olodaterol vs tiotropium on lung function, exercise capacity, and physical activity in patients with COPD.

Patients and methods: A total of 184 patients aged $\geq 40$ years with COPD (Global Initiative for Chronic Obstructive Lung Disease stage II-IV) received tiotropium/olodaterol for 6 weeks, then tiotropium for 6 weeks, or vice versa. The primary endpoint was inspiratory capacity (IC) at peak post-dose.

Results: Adjusted mean IC after 6-week treatment was $1.990 \mathrm{~L}$ with tiotropium/olodaterol vs $1.875 \mathrm{~L}$ with tiotropium (difference: $115 \mathrm{~mL}$; 95\% CI: 77, 153; $p<0.0001$ ). Forced expiratory volume in $1 \mathrm{~s}$ (difference: $105 \mathrm{~mL} ; 95 \% \mathrm{CI}: 88,123$ ), forced vital capacity (difference: $163 \mathrm{~mL}$; 95\% CI: 130, 197), and slow vital capacity (difference: $134 \mathrm{~mL} ; 95 \% \mathrm{CI}: 91,176)$ improved with tiotropium/olodaterol (all $p<0.0001$ ). Adjusted mean 6-min walk distance was similar between treatments in the overall population but was significantly increased with tiotropium/ olodaterol in the subgroup with Global Initiative for Chronic Obstructive Lung Disease stage III/IV at baseline (difference: $18.1 \mathrm{~m}$; 95\% CI: 2.3, 33.9; $p=0.0254$ ). In a post hoc analysis, tiotropium/olodaterol improved the values for $\geq 2.0$ metabolic equivalents (difference: $5.0 \mathrm{~min}$; 95\% CI: $0.4,9.7 ; p=0.0337$ ).

Conclusion: Tiotropium/olodaterol significantly improved IC compared with tiotropium and potentially enhanced the exercise capacity in COPD patients. A slight improvement in physical activity of relatively more than moderate intensity was also seen with tiotropium/olodaterol.

Keywords: Japanese, COPD, $\mathrm{FEV}_{1}, \mathrm{FVC}$, inspiratory capacity

\section{Introduction}

The prevalence of COPD is increasing worldwide, with an estimated 210 million cases in 2007. ${ }^{1}$ A sharp rise in the prevalence of COPD has been reported in developing countries, largely attributed to a combination of risk factors, particularly tobacco use. ${ }^{2}$ The World Health Organization reported that $\sim 3$ million deaths secondary to COPD occurred in 2015, and that the disease affects men and women almost equally. ${ }^{3}$

Bronchodilators are the first-line treatment for COPD, and inhaled long-acting bronchodilator use in newly diagnosed patients is associated with fewer hospital admissions and lower medical costs. ${ }^{4}$

Previous studies have shown that combination therapy of tiotropium, a long-acting muscarinic antagonist (LAMA), and olodaterol, a long-acting beta agonist (LABA), provides significantly improved lung function and quality of life, compared with either therapy used individually. ${ }^{5-7}$

Other Phase III studies in Western countries showed significant improvements in lung hyperinflation with an increase in inspiratory capacity (IC) after 6 or 12 weeks of treatment compared with monotherapy or placebo. ${ }^{8,9}$ 
However, there is limited evidence of significant improvements in exercise capacity with LAMA/LABA combination therapy, and few studies have compared the effects of the combination therapy with the respective monotherapy on physical activity; ${ }^{10-13}$ thus, a need remains for therapeutics that improve exercise capacity in patients with COPD.

This study investigated the efficacy of tiotropium/ olodaterol in terms of lung volume, exercise tolerability, and physical activity compared with that of tiotropium in COPD patients.

\section{Patients and methods}

\section{Patients}

Inclusion criteria were as follows: male and female Japanese patients aged $\geq 40$ years with COPD and stable airway obstruction with post-bronchodilator forced expiratory volume in $1 \mathrm{~s}\left(\mathrm{FEV}_{1}\right)<80 \%$ of predicted normal; Global Initiative for Chronic Obstructive Lung Disease (GOLD) grade II-IV, and post-bronchodilator $\mathrm{FEV}_{1} /$ forced vital capacity $(\mathrm{FVC})<70 \%$ at Visit 1 ; current or ex-smokers with a smoking history of $>10$ pack years; modified Medical Research Council $\geq 1$; 6-min walk distance (6MWD) test $<400 \mathrm{~m}$; and a score $\geq 4$ on the modified Borg scale of breath discomfort at the end of the 6MWD test at Visit 2.

The main exclusion criteria were the presence of a significant disease other than COPD; a clinically significant abnormality in hematology, blood chemistry, or urinalysis; and concurrent bronchial asthma. Patients who used daytime oxygen therapy for $>1$ hour per day were also excluded. Further details have been described elsewhere. ${ }^{14}$ Written informed consent was obtained from all patients prior to the study, which was approved by the institutional review board at each participating center (details of all institutional review boards are provided in Table S1).

\section{Study design}

This was a multicenter, randomized, double-blind, activecontrolled, two-way crossover trial (ClinicalTrials.gov Identifier NCT02629965). Details of the study design have been published previously. ${ }^{14}$

Patients were randomized in a 1:1 ratio via interactive response technology to receive tiotropium for 6 weeks followed by tiotropium/olodaterol for 6 weeks, or vice versa. Randomization was not stratified. The study sponsor (Boehringer Ingelheim) generated and stored the randomization schedule and prepared and coded the medication in a blinded fashion. Investigators and all individuals involved in trial conduct or analysis remained blinded to the randomized treatment until after data lock.

\section{Treatment}

Oral doses of tiotropium/olodaterol 5/5 $\mu \mathrm{g}$ inhalation solution (2.5/2.5 $\mu \mathrm{g}$ per actuation) and tiotropium $5 \mu \mathrm{g}$ inhalation solution (2.5 $\mu \mathrm{g}$ per actuation) were administered by RESPIMAT inhaler based on the marketed dose in Japan. Visit 1 consisted of a screening process carried out over a period of 2 weeks. At Visit 2, patients were randomly allocated to each group. The intervention group received once-daily tiotropium/olodaterol $5 / 5 \mu \mathrm{g}$ inhalation solution for 6 weeks, and patients in the second arm of the study received tiotropium $5 \mu \mathrm{g}$ inhalation solution over the same period. There was no placebo comparator in this trial.

Patients were instructed to inhale two puffs from the RESPIMAT inhaler, once a day, in the morning. All instances of trial medication taken were recorded using patient diaries indicating the number of puffs of salbutamol metered dose inhaler used. At Visit 3, patients received the crossover treatment without a washout period. Restricted treatments prior to the start of the study included any oral and patch $\beta$-adrenergic therapies, and oral corticosteroid medication at unstable doses (ie, $<6$ weeks on a stable dose) with doses in excess of the equivalent of $10 \mathrm{mg}$ prednisone per day or $20 \mathrm{mg}$ every other day.

\section{Study assessments}

Pulmonary function testing (Flowscreen; eResearch Technology GmbH, Estenfeld, Germany), 6MWD, and physical activity assessment occurred in visits $1-4$ /end of treatment (EOT); visits 1 and 4/EOT also included a physical examination of patients, including smoking status and, for female participants, a pregnancy test.

Lung capacity was assessed using IC at rest, measured at 60 min post-dose after 6 weeks of treatment. Exercise capacity and physical activity were measured using the 6MWD test and a 3-axis accelerometer (Active style PRO HJA-750C, HJA750C; OMRON, Kyoto, Japan), respectively. The patients were required to wear the accelerometer on the waist.

At the start of screening (Visit 1), Visit 2, Visit 3, and Visit 4/EOT, a complete physical examination was performed by the investigator. Follow-up examinations were scheduled for Visit 5 , if there were any clinically significant findings at Visit $4 /$ EOT. 
Standard 12-lead electrocardiogram (ECG) and vital sign monitoring at rest were performed on all patients at visits $1-4 /$ EOT.

\section{Efficacy outcomes Lung function}

The primary endpoint was IC at rest, measured at $60 \mathrm{~min}$ post-dose after 6 weeks of treatment.

The secondary endpoints were lung function $\left(\mathrm{FEV}_{1}\right.$, 30 min post-dose; FVC, 30 min post-dose; slow vital capacity [SVC], 60 min post-dose).

\section{The 6-min walk test}

The 6-min walk test (6MWT) was used to measure exercise capacity associated with dynamic hyperinflation. The analysis of the 6MWD was also conducted in several subgroups. The 6MWT was terminated when percutaneous oxygen saturation by pulse oximetry $\left(\mathrm{SpO}_{2}\right)$ decreased to $<83 \%$ at any time after the patient began walking. $6 \mathrm{MWD}$ was also analyzed only in patients who completed the 6MWT.

\section{Physical activity}

Physical activity was measured with a 3-axis accelerometer using average number of steps/day, average daily duration ( $\min$ ) of $\geq 4, \geq 3$, and $\geq 2$ metabolic equivalents (METs), and average daily active strength (METs min) of $\geq 3$ METs during the last 2 weeks of 6 weeks of treatment. In this study, 24 hours of measurement were performed each day, except during bathing or water sport activities. Because it has been reported that exclusion of non-wearing time may increase the accuracy of physical activity measurement, we conducted a post hoc analysis based on previously reported methodologies; in this analysis, data for patients with $<8$ hours wearing time and less than two valid days were excluded. ${ }^{15,16}$

\section{Safety}

Safety endpoints were all adverse events (AEs) (including physical examination, vital sign monitoring, 12-lead ECG, and laboratory tests) until the end of the study, in addition to heart rate and $\mathrm{SpO}_{2}$ in conjunction with the 6MWT.

\section{Statistical methods}

Details of the study populations and sample size calculations (Supplementary materials) are given in the published study design paper. ${ }^{14}$

Primary endpoint analysis (IC at rest) was conducted using a mixed-effects model repeated-measures (SAS procedure MIXED) approach, with treatment and period as categorical fixed effects, study baseline (Visit 2) as a covariate, and patient as a random effect.

Adjusted mean values and treatment contrasts are presented with 95\% CIs.

Secondary and further endpoints were analyzed using a similar model with descriptive statistics provided for both treatments.

A two-sided significance level of $5 \%$ was used to test the primary endpoint. The analysis of secondary and further endpoints was not adjusted for multiplicity, and the corresponding $p$-values for treatment comparisons are descriptive (nominal $p$-values). All statistical analyses were performed using validated SAS (SAS Institute Inc., Cary, NC, USA) macros, customized at Boehringer Ingelheim (Ingelheim am Rhein, Germany).

\section{Ethics approval and informed consent}

Written informed consent was obtained from all patients prior to the study, which was approved by the institutional review board at each participating center. The study was conducted according to the principles of the International Conference on Harmonisation and Good Clinical Practice, Declaration of Helsinki, Japanese Good Clinical Practice, and all relevant local regulatory, legal, and ethical requirements.

\section{Results \\ Patients}

In total, 334 patients from 44 medical institutions provided written informed consent. Of these, 184 patients were entered into the investigational treatment period and 150 patients were excluded at screening. Reasons for the exclusions were a $6 \mathrm{MWD}$ of $>400 \mathrm{~m}$, a modified Borg scale score of $<4$, achieving $\geq 80 \% \mathrm{FEV}_{1}$ in pulmonary testing, experiencing an $\mathrm{AE}$, and withdrawal of consent. After randomization, seven patients discontinued treatment, four because of AEs, two withdrew consent, and one for other reasons (Figure 1).

The majority of the study participants were male (89.7\%). Mean (SD) age was 72.8 (7.1) years, mean (SD) body mass index was $22.2(4.0) \mathrm{kg} / \mathrm{m}^{2}$ (Table 1), and mean (SD) duration of COPD was 5.49 (4.28) years.

Study medication compliance for tiotropium/olodaterol was $98.9 \%$, with $97.8 \%$ recorded for tiotropium.

\section{Primary endpoint}

Significant improvements were achieved for tiotropium/ olodaterol vs tiotropium: the adjusted mean IC after 6 weeks of treatment was $1.990 \mathrm{vs} 1.875 \mathrm{~L}$, respectively, corresponding 


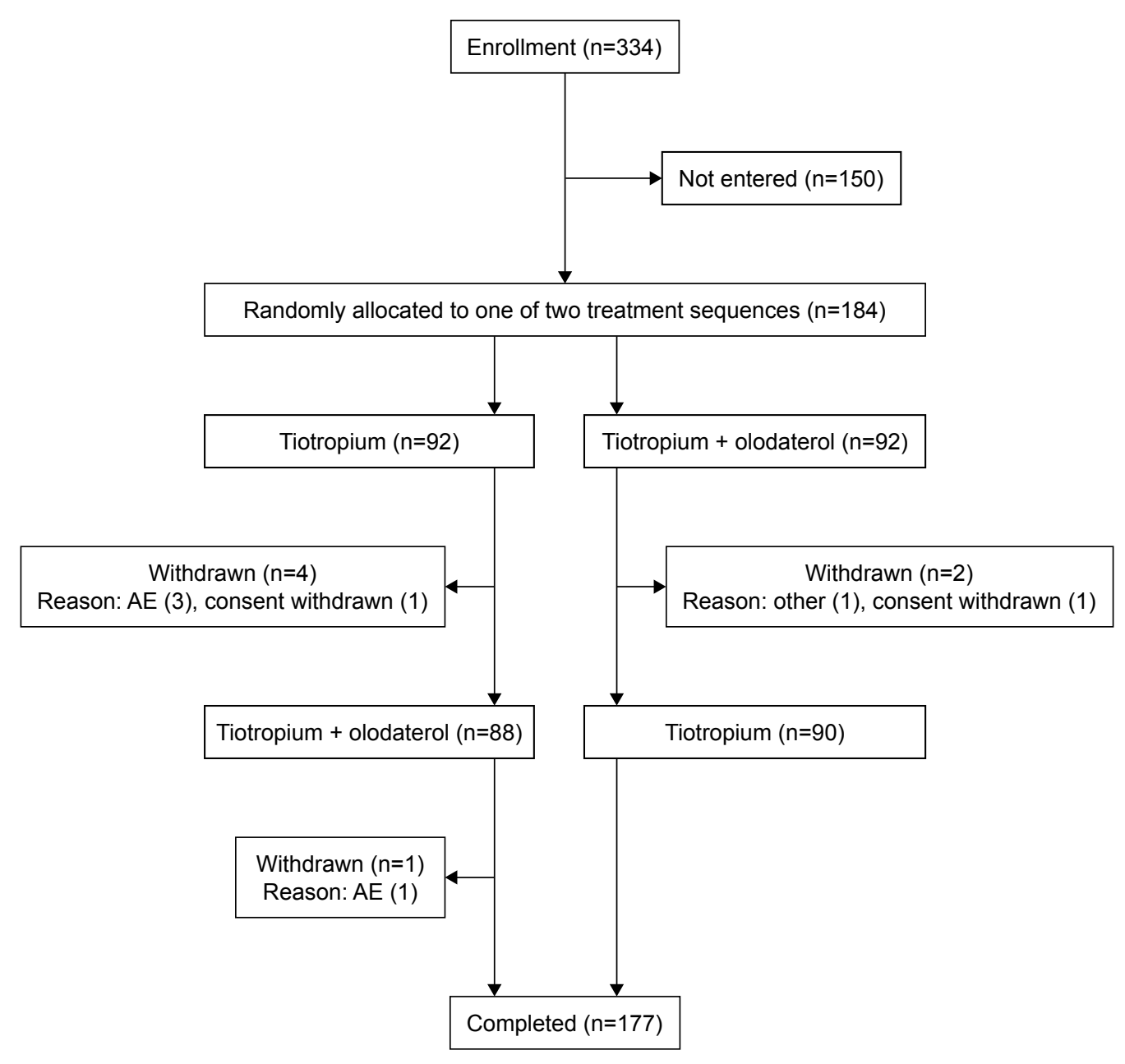

Figure I Patient disposition.

Abbreviation: $\mathrm{AE}$, adverse event.

to an increase of $115 \mathrm{~mL}(95 \% \mathrm{CI}: 77 \mathrm{~mL}, 153 \mathrm{~mL})$ in IC with tiotropium/olodaterol ( $p<0.0001$; Figure 2A).

\section{Secondary endpoints}

Significant improvements were seen for tiotropium/ olodaterol vs tiotropium in FVC (difference: $163 \mathrm{~mL}$; 95\% CI: $130 \mathrm{~mL}, 197 \mathrm{~mL}$; Figure 2B), $\mathrm{FEV}_{1}$ (difference: $105 \mathrm{~mL}$; 95\% CI: $88 \mathrm{~mL}, 123 \mathrm{~mL}$; Figure 2C), and SVC (difference: $134 \mathrm{~mL}$; 95\% CI: $91 \mathrm{~mL}, 176 \mathrm{~mL}$; Figure 2D), respectively (all $p<0.0001$ ).

The adjusted mean 6MWD after 6 weeks of treatment was similar between tiotropium/olodaterol and tiotropium in the overall population; the adjusted mean difference was 4.2 m (95\% CI: $-6.2 \mathrm{~m}, 14.5 \mathrm{~m} ; p=0.4291)$. Subgroup analyses according to GOLD stage were pre-specified, and the differences in adjusted mean 6MWD between tiotropium/ olodaterol and tiotropium treatments, by GOLD stage subgroup, are shown in Table S2.
Because only 16 patients ( $8.7 \%$ of total) were categorized as GOLD IV, the combined GOLD III and IV subgroups were analyzed post hoc. An increase in 6MWD with tiotropium/ olodaterol vs tiotropium was observed in the GOLD stage III/IV subgroup (adjusted mean difference $=18.1 \mathrm{~m}$ [95\% CI: 2.3 m, 33.9 m; $p=0.0254$; Figure 3]). Assessment of the 6MWD was terminated if the patient's $\mathrm{SpO}_{2}$ fell below $83 \%$, in order to assure patient safety. In total, 57 patients (32.8\%) could not complete the 6MWD test during the treatment period. In a post hoc analysis, patients who completed the 6MWT during the treatment period without desaturation achieved $357.3 \mathrm{~m}$ (tiotropium/olodaterol) vs $346.6 \mathrm{~m}$ (tiotropium), as shown in Figure 3C; between treatment difference $=10.7 \mathrm{~m}$ (95\% CI: $4.2 \mathrm{~m}, 17.3 \mathrm{~m} ; p=0.00014)$.

No significant differences were found for physical activity between the two treatments in terms of mean number of steps per day or daily duration of activity. The results are presented in the Supplementary materials. However, in a 
Table I Patient characteristics and demographics

\begin{tabular}{|c|c|}
\hline Characteristic & Total $(n=184)$ \\
\hline \multicolumn{2}{|l|}{ Sex, n (\%) } \\
\hline Male & $165(89.7)$ \\
\hline Female & $19(10.3)$ \\
\hline Age, years, mean (SD) & $72.8(7.1)$ \\
\hline Weight, kg, mean (SD) & $58.7(12.1)$ \\
\hline Height, cm, mean (SD) & I62.5 (7.1) \\
\hline Body mass index, kg/m², mean (SD) & $22.2(4.0)$ \\
\hline \multicolumn{2}{|l|}{ Smoking status, n (\%) } \\
\hline Ex-smoker & $152(82.6)$ \\
\hline Current smoker & $32(17.4)$ \\
\hline Smoking history, pack-years, mean (SD) & $61.0(28.5)$ \\
\hline \multicolumn{2}{|l|}{ Pulmonary function data, mean (SD) } \\
\hline FEV, post-bronchodilator, L & $1.228(0.407)$ \\
\hline FEV , change from pre-bronchodilator, $\mathrm{L}$ & $0.097(0.103)$ \\
\hline $\mathrm{FEV}, \%$ change from pre-bronchodilator & $10.619(11.215)$ \\
\hline$\%$ Predicted normal FEV ${ }_{1}^{a}$ & $52.629(15.207)$ \\
\hline FVC, L & $2.952(0.656)$ \\
\hline $\mathrm{FEV}_{1} / \mathrm{FVC}, \%$ & $41.803(10.685)$ \\
\hline IC, L & $1.822(0.488)$ \\
\hline SVC, L & $2.879(0.652)$ \\
\hline \multicolumn{2}{|l|}{ FEV, category, n (\%) } \\
\hline GOLD $2(\geq 50-<80 \%)$ & $100(54.3)$ \\
\hline GOLD $3(\geq 30-<50 \%)$ & $68(37.0)$ \\
\hline GOLD 4 (<30\%) & $16(8.7)$ \\
\hline \multicolumn{2}{|l|}{ 6MWT } \\
\hline Distance traveled, $\mathrm{m}$ & $293.8(93.3)$ \\
\hline Patient discontinued, n (\%) & $20(10.9)$ \\
\hline $\mathrm{SpO}_{2}$ decrease $<83 \%{ }^{\text {b }}$ n (\%) & $56(30.4)$ \\
\hline 6MWT stopped prematurely, n (\%) & $52(28.3)$ \\
\hline $\mathrm{SpO}_{2}$ (before exercise) & $94.0(2.32)$ \\
\hline $\mathrm{SpO}_{2}$ (end of exercise) & $88.4(5.11)$ \\
\hline $\mathrm{SpO}_{2}$ at $5 \mathrm{~min}$ after & $94.8(2.33)$ \\
\hline Pulse rate, bpm (before exercise) & $75.4($ (II.9) \\
\hline Pulse rate, bpm (end of exercise) & $97.2(14.7)$ \\
\hline Pulse rate at $5 \mathrm{~min}$ after, bpm & $77.1(13.0)$ \\
\hline \multicolumn{2}{|l|}{ Average daily duration of METs, mean (SD) } \\
\hline$\geq 2$ METs, $\min$ & $181.4(82.0)$ \\
\hline$\geq 3$ METs, min & $47.4(30.2)$ \\
\hline$\geq 4$ METs, $\min$ & $10.7(10.8)$ \\
\hline $\begin{array}{l}\text { Average daily active strength of } \geq 3 \text { METs } \\
(\min M E T s) \text {, mean (SD) }\end{array}$ & $157.0(101.1)$ \\
\hline mMRC dyspnea score, mean (SD) & $1.9(0.7)$ \\
\hline CAT total score, mean (SD) & $16.6(7.5)$ \\
\hline \multicolumn{2}{|l|}{ Concomitant therapy at baseline, $n(\%)$} \\
\hline LAMA & $119(64.7)$ \\
\hline LABA & II (6.0) \\
\hline ICS/LABA & $8(4.3)$ \\
\hline ICS/LAMA & $38(20.7)$ \\
\hline LAMA/LABA & $0(0.0)$ \\
\hline LAMA/LABA/ICS & $0(0.0)$ \\
\hline
\end{tabular}

Notes: ${ }^{\text {Based }}$ on predicted values defined by the European Community for Steel and Coal. 'Including two missing data.

Abbreviations: 6MWT, 6-min walk test; bpm, beats per minute; CAT, COPD assessment test; $\mathrm{FEV}_{1}$, forced expiratory volume in I s; FVC, forced vital capacity; GOLD, Global Initiative for Chronic Obstructive Lung Disease; IC, inspiratory capacity; ICS, inhaled corticosteroid; LABA, long-acting beta-2-agonist; LAMA, long-acting muscarinic antagonist; METs, metabolic equivalents; mMRC, modified Medical Research Council; $\mathrm{SpO}_{2}$, oxygen saturation by pulse oximetry; SVC, slow vital capacity. post hoc analysis, excluding the non-wearing time (mean wearing time of accelerometer was 14.3 hours in tiotropium/olodaterol and 14.2 hours in tiotropium; tiotropium/ olodaterol: $n=163$, tiotropium: $n=167$ ), tiotropium/olodaterol improved the values for 2.0 METs (186.5 vs $191.5 \mathrm{~min}$, difference: $5.0 \mathrm{~min}$; 95\% CI: $0.4 \mathrm{~min}, 9.7 \mathrm{~min} ; p=0.0337$ ), but no difference was seen for steps (3,871 vs 3,794 steps, difference: 78 steps; $95 \%$ CI: -93 steps, 248 steps) compared with tiotropium (Figure 4).

\section{AEs}

A total of four patients discontinued the study owing to AEs.

The incidences of AEs, serious AEs, drug-related AEs, and AEs leading to discontinuation were similar between tiotropium/olodaterol and tiotropium treatments. The most frequent AEs were viral upper respiratory tract infection (tiotropium/olodaterol: 10.0\%, tiotropium: 6.0\%), followed by worsening COPD (tiotropium/olodaterol: $5.0 \%$, tiotropium: $4.9 \%$ ). Individual events with an incidence $\geq 2 \%$ are shown in Table 2.

There were no differences in pulse rate or $\mathrm{SpO}_{2}$ in conjunction with the 6MWT. Mean (SD) pulse rate for the treated population was 75.4 (11.9), 97.2 (14.7), and 77.1 (13.0) beats per minute before, after, and $5 \mathrm{~min}$ after the end of the 6MWT, respectively.

$\mathrm{SpO}_{2}$ was $94.0 \%$ for tiotropium/olodaterol and $94.0 \%$ for tiotropium just before the test, $88.4 \%$ for tiotropium/ olodaterol and $88.5 \%$ for tiotropium just after the test, and $94.8 \%$ for tiotropium/olodaterol and $94.8 \%$ for tiotropium 5 min after the test.

There were no clinically relevant changes in vital signs, laboratory parameters, or 12-lead ECG parameters.

\section{Discussion}

In the VESUTO ${ }^{\circledR}$ study, Japanese patients with COPD were treated with tiotropium/olodaterol to evaluate the effects on lung hyperinflation, exercise capacity, and physical activity levels.

Results for the primary outcome of IC ( 60 min post-dose) after 6 weeks of treatment with tiotropium/olodaterol showed a significant increase of $115 \mathrm{~mL}$ compared with tiotropium $(p<0.0001)$; thus, tiotropium/olodaterol therapy reduced lung hyperinflation in Japanese patients with COPD.

This result is comparable with that achieved in the MORACTO studies for $5 / 5 \mu \mathrm{g}$ tiotropium/olodaterol vs tiotropium: study 1, IC (120 min post-dose) adjusted mean (standard error) $=114 \mathrm{~mL}(0.027)$; study 2 , IC (120 min postdose) adjusted mean ( standard error) $=88 \mathrm{~mL}(0.025){ }^{9}$ 
A
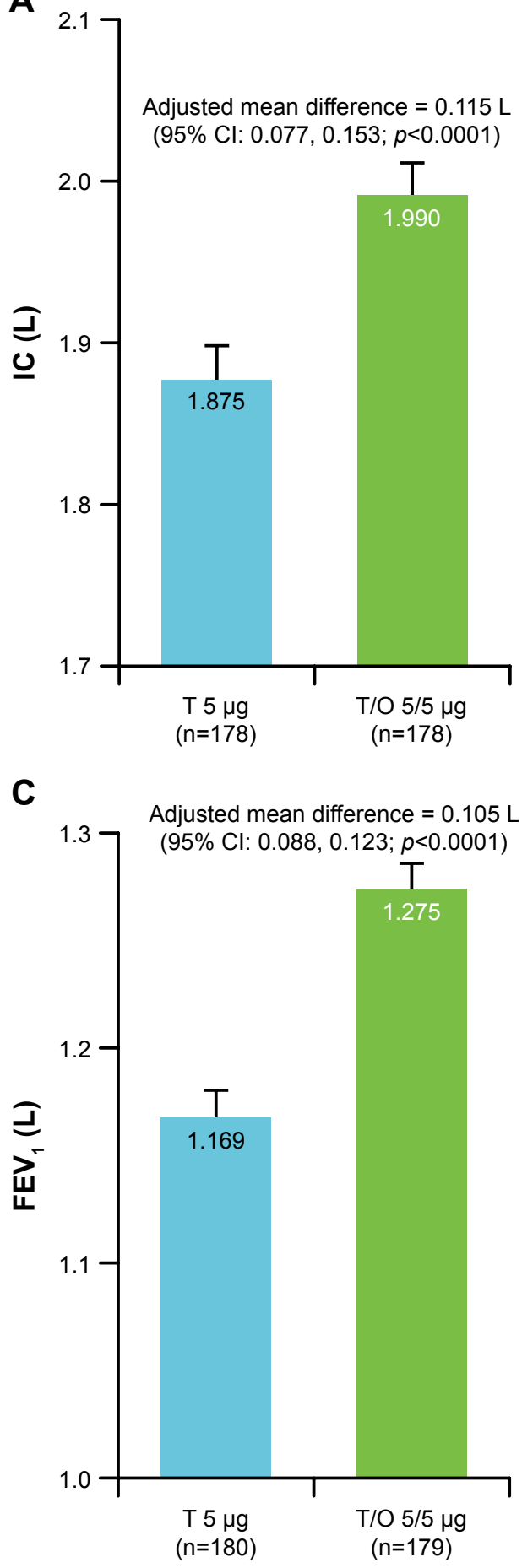

B

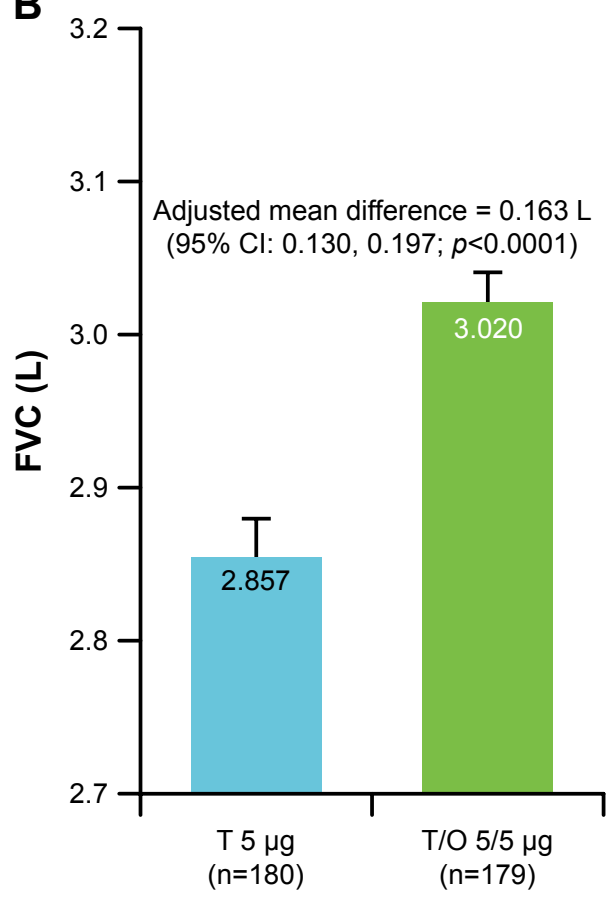

D

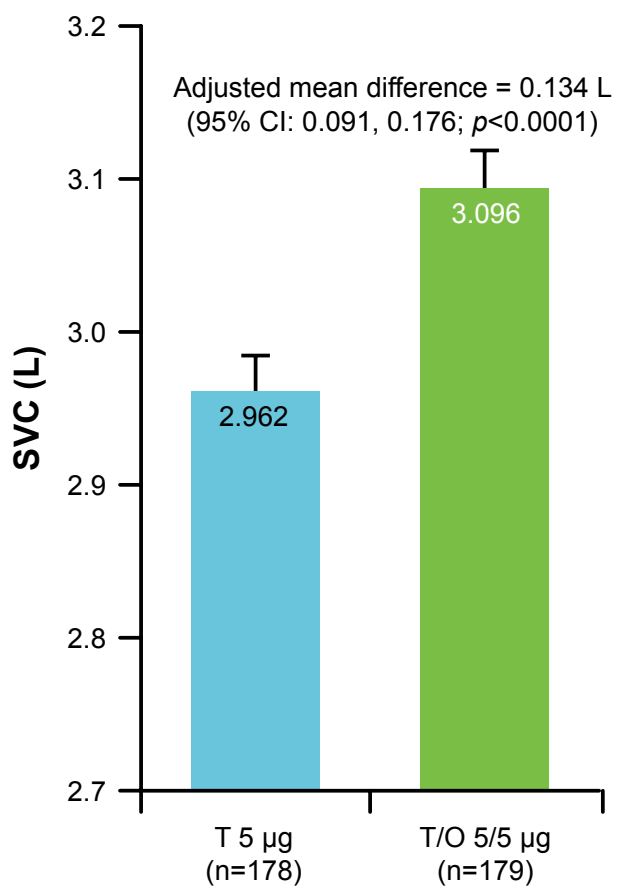

Figure $2 \mathrm{IC}$ and lung function parameters after 6 weeks of treatment with $\mathrm{T}$ or $\mathrm{T} / \mathrm{O}$.

Notes: (A) IC 60 min post-dose. (B) FVC 30 min post-dose. (C) FEV, in I s 30 min post-dose. (D) SVC 60 min post-dose.

Abbreviations: $\mathrm{FEV}_{1}$, forced expiratory volume in I s; FVC, forced vital capacity; IC, inspiratory capacity; SVC, slow vital capacity; T, tiotropium; T/O, tiotropium/olodaterol.

Improvements were also realized for tiotropium/olodaterol vs tiotropium in lung function for $\mathrm{FEV}_{1}$, $\mathrm{SVC}$, and $\mathrm{FVC}$. Although certain baseline characteristics of Japanese patients with COPD differ from those of Western patients, this study shows that the effects of tiotropium/olodaterol on lung function are consistent across Japanese and Western patients.
The VESUTO study is the first head-to-head comparison trial between tiotropium/olodaterol and tiotropium, and provided the first evidence for the evaluation of IC in Japanese patients with COPD.

The 6MWD assessment is a common tool to evaluate restricted exercise capacity caused by lung hyperinflation 


\section{A}

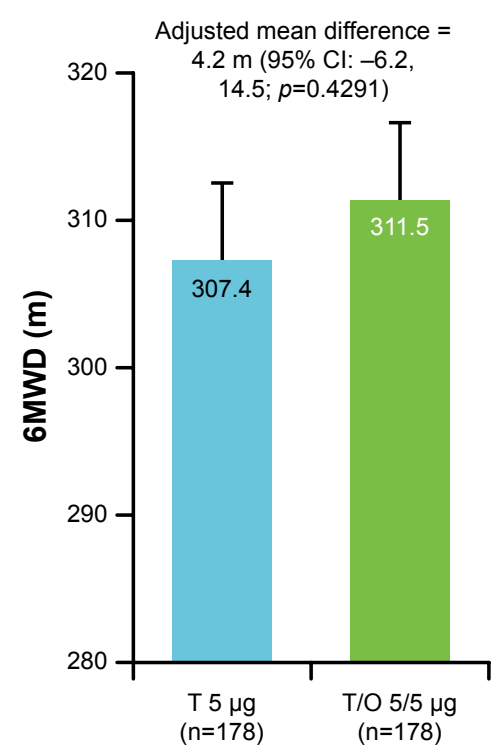

B

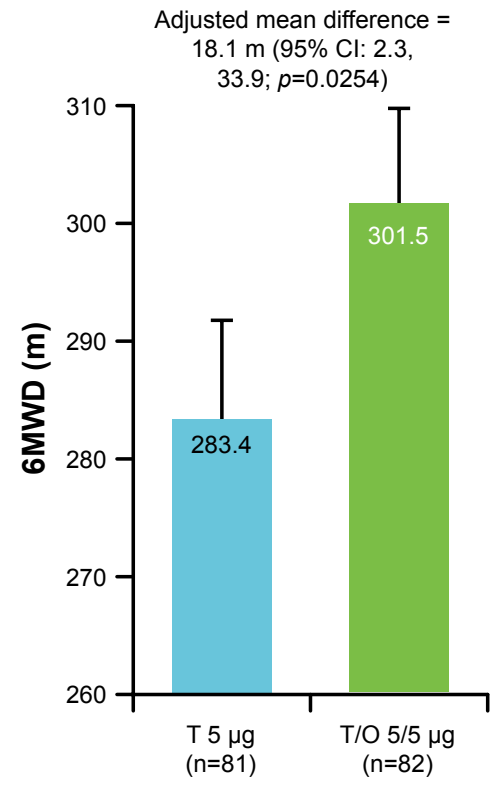

C

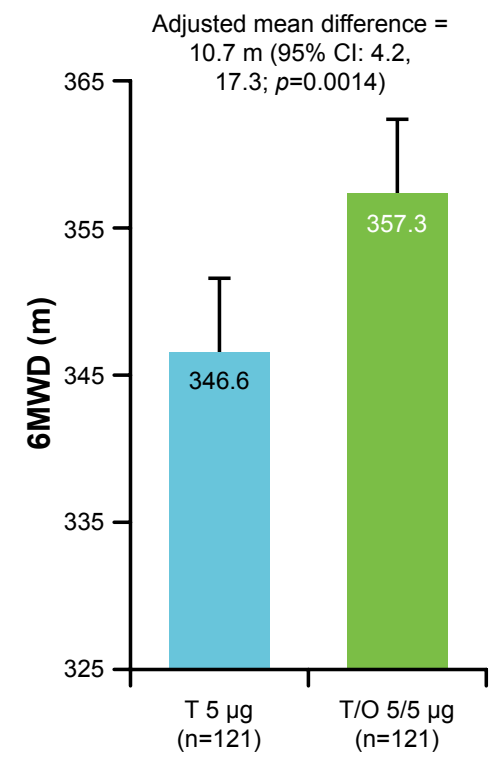

Figure 3 6MWD after 6 weeks of treatment with T or T/O.

Notes: (A) Overall population. (B) GOLD III/IV patients. (C) Six-minute walk test completers.

Abbreviations: 6MWD, 6-min walk distance; GOLD, Global Initiative for Chronic Obstructive Lung Disease; T, tiotropium; T/O, tiotropium/olodaterol.

and an important IC correlation measurement and predictor of increased mortality in COPD. ${ }^{17-19}$ To our knowledge, no other randomized controlled trial has compared combined LAMA/LABA therapy to a monotherapy on the 6MWD. ${ }^{20}$

It has been demonstrated that IC improved more in patients with severe GOLD stages, ${ }^{8,21}$ which suggests that the 6MWD could also be improved more in such patients; therefore, analyses on 6MWD in subgroups of GOLD stages were considered to be a clinically meaningful evaluation of 6MWD. Subgroup analyses in VESUTO provide evidence that 6MWD was improved more in the GOLD III/IV patients receiving tiotropium/olodaterol than in those receiving tiotropium (by $18 \mathrm{~m} ; 95 \%$ CI: $2.3 \mathrm{~m}, 33.9 \mathrm{~m} ; p=0.0254$ ), although the adjusted mean of 6MWD after 6 weeks of treatment was
A

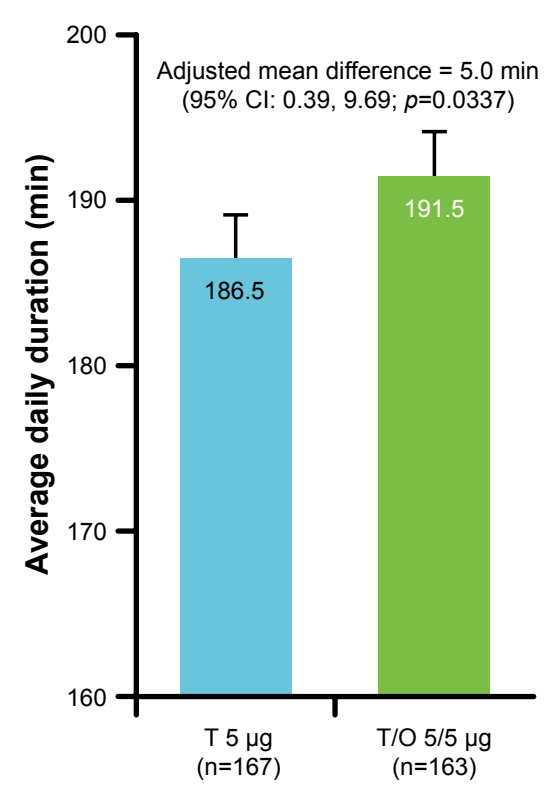

B

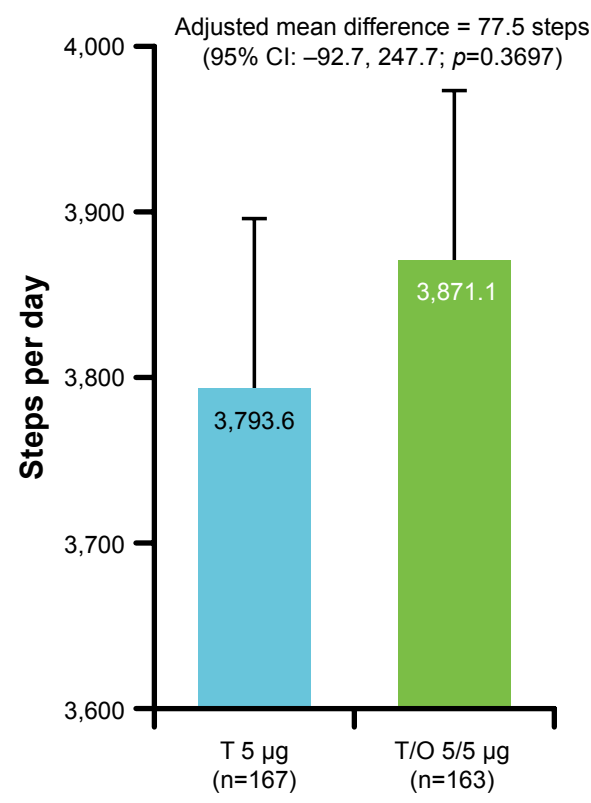

Figure 4 Physical activity after 6 weeks of treatment with T or T/O, excluding individuals with $<8$ hours wearing time or less than 2 valid days. Notes: (A) Average daily duration of activity $\geq 2$ METs. (B) Average number of steps per day. Abbreviations: METs, metabolic equivalents; T, tiotropium; T/O, tiotropium/olodaterol. 
Table 2 Adverse events

\begin{tabular}{|c|c|c|}
\hline Adverse event & $\begin{array}{l}\text { T } 5 \mu \mathrm{g}, \\
(\mathrm{n}=182)\end{array}$ & $\begin{array}{l}\text { T/O 5/5 } \mu \mathrm{g}, \\
(\mathrm{n}=180)\end{array}$ \\
\hline \multicolumn{3}{|l|}{ AEs, n (\%) } \\
\hline Any AE & $63(34.6)$ & $68(37.8)$ \\
\hline Severe AEs & $3(1.6)$ & $4(2.2)$ \\
\hline Drug-related $\mathrm{AE}^{\mathrm{a}}$ & $8(4.4)$ & $6(3.3)$ \\
\hline AEs leading to discontinuation & $3(1.6)$ & I (0.6) \\
\hline \multicolumn{3}{|l|}{ AEs with an incidence $\geq 2 \%$} \\
\hline Viral upper respiratory tract infection & II (6.0) & $18(10.0)$ \\
\hline Worsening COPD & $9(4.9)$ & $9(5.0)$ \\
\hline Worsening bronchitis & $3(1.6)$ & $3(1.7)$ \\
\hline Fall & $\mathrm{I}(0.5)$ & $5(2.8)$ \\
\hline Pneumonia & $3(1.6)$ & I (0.6) \\
\hline Hyperuricemia & $\mathrm{I}(0.5)$ & $3(1.7)$ \\
\hline Thirst & $\mathrm{I}(0.5)$ & $3(1.7)$ \\
\hline
\end{tabular}

Note: anvestigator determined.

Abbreviations: $\mathrm{AE}$, adverse event; $\mathrm{T}$, tiotropium; $\mathrm{T} / \mathrm{O}$, tiotropium/olodaterol.

similar between tiotropium/olodaterol and tiotropium in the overall population.

The improvement seen in exercise capacity did not reach the minimum clinically important difference for 6MWD in COPD $(25-33 \mathrm{~m}),{ }^{22}$ indicating that bronchodilator treatment alone may not be sufficient to provide clinical benefit in exercise capacity. ${ }^{19}$ However, bronchodilator treatment taken over longer periods in combination with pulmonary rehabilitation may further improve exercise capacity. ${ }^{23}$

In this study, desaturation prevented 57 patients $(32.8 \%)$ from completing the 6MWT during the treatment periods. $\mathrm{SpO}_{2}$ levels were carefully monitored throughout the 6MWT, and the 6MWT was immediately terminated if $\mathrm{SpO}_{2}$ levels fell below $83 \%$, although the patients could continue the $6 \mathrm{MWT}$. Careful monitoring of $\mathrm{SpO}_{2}$ is required during the $6 \mathrm{MWT}$ due to increased mortality levels in patients who experience desaturation, although the underlying mechanisms are unclear. ${ }^{24}$

Physical activity decreases in patients with COPD with increasing age, and this may be the greatest risk factor for death. Without intervention, patients experience a worsening in quality of life and prognosis..$^{25,26}$

GOLD recommends maintenance of exercise capacity, ${ }^{27}$ and the COPD guidelines of the Japanese Respiratory Society also recommend improvement of exercise capacity and physical activity as a treatment goal. ${ }^{28}$

Previous studies on the effects of several different bronchodilators on physical activity showed inconsistent findings. ${ }^{29}$ In particular, two studies on LAMA/LABA combination therapy were placebo controlled. ${ }^{12,13}$

The VESUTO study is the first to compare the effects of LAMA/LABA combination therapy to LAMA or LABA monotherapy on physical activity without any behavioral intervention.

In our study, no significant differences were noted between tiotropium/olodaterol and tiotropium treatments in the mean number of steps/day, or the mean daily duration of activity $\geq 2,3$, and 4 METs during the last 2 weeks of the 6-week treatment in the overall population. One reason for this might be that patients had low baseline activity and were unlikely to achieve improvement in activity with pharmacologic intervention alone (baseline activity: 3,723 steps; 2 METs, 182.5 min; 3 METs, 47.9 min, 10.8 min; 4 METs).

We conducted a post hoc analysis based on previously reported methodologies, excluding data for patients with $<8$ hours wearing time ${ }^{15}$ and less than 2 valid days. ${ }^{16}$ The analysis showed greater separation between tiotropium/ olodaterol and tiotropium treatments in 2 METs. Although a clinically meaningful difference is unclear, these factors need to be considered in order to assess physical activity in further studies.

Evidence from previous studies indicates that improvements in physical activity levels of patients with COPD can be achieved through patient education, rehabilitation, and motivation. ${ }^{30,31}$ The outcomes of the VESUTO study indicate that a comprehensive approach including pharmacologic treatment may strengthen these results.

\section{Limitations}

The study population was limited to Japanese patients mostly males - with COPD with a modified Medical Research Council $\geq 1,6 \mathrm{MWD}<400 \mathrm{~m}$, and modified Borg scale $\geq 4$, and was relatively short, meaning long-term investigation is needed to confirm the results. These characteristics limit generalizability to other populations and females. All tests were performed at post-dose levels, and future studies are needed to investigate the 24-hour trough efficacy for exercise capacity. However, our results support and expand on current knowledge.

\section{Conclusion}

Tiotropium/olodaterol therapy demonstrated a significant improvement in hyperinflation compared with tiotropium and showed a potential enhancement of exercise capacity in COPD patients. A slight improvement in physical activity of relatively more than moderate intensity was also seen in tiotropium/olodaterol; however, additional studies may be needed to further explore physical activity. There were no safety concerns or serious adverse effects reported. 


\section{Acknowledgments}

We thank all the patients involved in this study. We also thank the following investigators for their assistance in conducting this study: Osamu Hataji, Matsusaka City Hospital, Matsusaka, Mie, Japan; Yuji Higashimoto, Kindai University Hospital, Osakasayama, Osaka, Japan; Yasuhiro Kondoh, Tosei General Hospital, Seto, Aichi, Japan; Masaru Suzuki, Hokkaido University Hospital, Sapporo, Hokkaido, Japan; Hiroyuki Ohbayashi, Tohno Chuo Clinic, Mizunami, Gifu, Japan; Takefumi Saito, NHO Ibarakihigashi National Hospital, Naka-gun, Ibaraki, Japan; Kazuhisa Asai, Osaka City University Hospital, Osaka, Japan; Motohiko Miura, Japan Organization of Occupational Health and Safety Tohoku Rosai Hospital, Sendai, Miyagi, Japan; Naoki Miyao, Medical Corporation Kokankai Kokan Clinic, Kawasaki, Kanagawa, Japan; Hirotaka Nagashima, Shinjuku Research Park Clinic, Shinjuku-ku, Tokyo, Japan; Hisatoshi Sugiura, Tohoku University Hospital, Sendai, Miyagi, Japan; Toshiyuki Harada, Japan Community Health Care Organization Hokkaido Hospital, Sapporo, Hokkaido, Japan; Tetsuo Hiramatsu, Hiramatsu Internal and Respiratory Medicine Clinic, Komaki, Aichi, Japan; Michiko Tsuchiya, Rakuwakai Otowa Hospital, Kyoto, Japan; Takashi Kinoshita, Kurume University Hospital, Kurume, Fukuoka, Japan; Tohru Tsuda, Kirigaoka Tsuda Hospital, Kitakyushu, Fukuoka, Japan; Shigeo Muro, Kyoto University Hospital, Kyoto, Japan; Yu Utsumi, Iwate Medical University Hospital, Morioka, Iwate, Japan; Toshio Ichiwata, Tokyo Medical University Hachioji Medical Center, Hachioji, Tokyo, Japan; Masahiro Kaneko, Kobe City Hospital Organization Kobe City Medical Center West Hospital, Kobe, Hyogo, Japan; Takuya Samukawa, Kagoshima University Hospital and Dental Hospital, Kagoshima, Japan; Takashi Motegi, Respiratory Care Clinic, Nippon Medical School, Chiyoda-ku, Tokyo, Japan; Yoshiaki Minakata, NHO Wakayama Hospital, Hidaka-gun, Wakayama, Japan; Satoshi Fuke, KKR Sapporo Medical Center, Sapporo, Hokkaido, Japan; Motokazu Kato, Kishiwada City Hospital, Kishiwada, Osaka, Japan; Yasuhiro Gon, Nihon University Itabashi Hospital, Itabashi-ku, Tokyo, Japan; Atsushi Nagai, Shinyurigaoka General Hospital, Kawasaki, Kanagawa, Japan; Hiromasa Harada, Yao Tokushukai General Hospital, Yao, Osaka, Japan; Keisuke Tomii, Kobe City Medical Center General Hospital, Kobe, Hyogo, Japan; Yasuko Harada, Nishi Fukuoka Hospital, Fukuoka, Japan; Masahiko Saito, Uji Tokushukai Medical Center, Uji, Kyoto, Japan; Tadashi Sato, Juntendo University Hospital, Bunkyo-ku, Tokyo, Japan; Hironori Sagara, Showa University Hospital, Shinagawa-ku,
Tokyo, Japan; Hiroyuki Nakamura, Sakaide City Hospital, Sakaide, Kagawa, Japan; Yusuke Shikama, Showa University Fujigaoka Hospital, Yokohama, Kanagawa, Japan; Shinichi Osaki, Osaki Internal and Respiratory Clinic, Kitakyushu, Fukuoka, Japan; Koichi Nishimura, National Center for Geriatrics and Gerontology, Obu, Aichi, Japan; Hiroyuki Koba, Teine Keijinkai Clinic, Sapporo, Hokkaido, Japan; Keisuke Miki, NHO Toneyama National Hospital, Toyonaka, Osaka, Japan; Yuriko Mizobe, Nihonbashi Sakura Clinic, Chuo-ku, Tokyo, Japan; Yojiro Onari, Mazda Hospital, Aki-gun, Hiroshima, Japan; Hiroshi Hayakawa, NHO Tenryu Hospital, Hamamatsu, Shizuoka, Japan; Tetsuji Kawamura, NHO Himeji Medical Center, Himeji, Hyogo, Japan; Takeshi Isobe, Shimane University Hospital, Izumo, Shimane, Japan. Medical writing assistance was provided by Allison Kirsop, PhD, and Marion Barnett of Edanz Medical Writing, with publication management and editorial support by Daisuke Kuroki of Nippon Boehringer Ingelheim. This study was funded by Nippon Boehringer Ingelheim Co., Ltd. Nippon Boehringer Ingelheim contributed to the design of the study, data collection, analysis, and interpretation of the study results. Nippon Boehringer Ingelheim also funded the medical writing support, publication charges, and open access fee for publication of this manuscript.

\section{Author contributions}

All named authors meet the International Committee of Medical Journal Editors criteria for authorship for this manuscript. MI, YM, TM, JU, TS, TA, and KH contributed to the study design, YG contributed to the data collection, TA analyzed data, and all authors contributed to the interpretation of the data. MI led the drafting of the manuscript. All authors contributed toward data analysis, drafting and revising the paper, and agree to be accountable for all aspects of the work.

\section{Disclosure}

TS and SN are employees of Nippon Boehringer Ingelheim. MI has received honoraria from AstraZeneca, Nippon Boehringer Ingelheim, and Novartis Pharma. YG has received honoraria from Nippon Boehringer Ingelheim, AstraZeneca, Novartis Pharma and KYORIN Pharmaceutical Co., Ltd. TM reports honoraria from Nippon Boehringer Ingelheim and Fukuda Life Tech. JU has received honoraria from Nippon Boehringer Ingelheim, Hoshi Iryo-Sanki, and Teijin Pharma. $\mathrm{YM}$ and $\mathrm{KH}$ have received honoraria from Nippon Boehringer Ingelheim. TA received compensation from Nippon Boehringer Ingelheim for statistical analysis service. The authors report no other conflicts of interest in this work. 


\section{References}

1. Bousquet J, Khaltaev N, editors. Global Surveillance, Prevention and Control of Chronic Respiratory Diseases: A Comprehensive Approach. Geneva: World Health Organisation; 2007.

2. Barnes PJ. Chronic obstructive pulmonary disease. Preface Clin Chest Med. 2014;35(1):13.

3. WHO [webpage on the Internet]. COPD factsheet. Published November 2016. Available from: http://www.who.int/mediacentre/factsheets/ fs315/en/. Accessed October 8, 2017.

4. Kim J, Kim K, Kim Y, et al. The association between inhaled longacting bronchodilators and less in-hospital care in newly-diagnosed COPD patients. Respir Med. 2014;108(1):153-161.

5. Buhl R, Maltais F, Abrahams R, et al. Tiotropium and olodaterol fixeddose combination versus mono-components in COPD (GOLD 2-4). Eur Respir J. 2015;45:969-979.

6. Beeh KM, Westerman J, Kirsten AM, et al. The 24-h lung-function profile of once-daily tiotropium and olodaterol fixed-dose combination in chronic obstructive pulmonary disease. Pulm Pharmacol Ther. 2015; 32:53-59.

7. Singh D, Ferguson GT, Bolitschek J, et al. Tiotropium + olodaterol shows clinically meaningful improvements in quality of life. Respir Med. 2015;109(10):1312-1319.

8. Maltais F, Kirsten AM, Hamilton A, De Sousa D, Voß F, Decramer M. Evaluation of the effects of olodaterol on exercise endurance in patients with chronic obstructive pulmonary disease: results from two 6-week crossover studies. Respir Res. 2016;17(1):77.

9. O'Donnell DE, Casaburi R, Frith P, et al. Effects of combined tiotropium/olodaterol on inspiratory capacity and exercise endurance in COPD. Eur Respir J. 2017;49(4):pii: 1601348.

10. Beeh KM, Korn S, Beier J, et al. Effect of QVA149 on lung volumes and exercise tolerance in COPD patients: the BRIGHT study. Respir Med. 2014;108(4):584-592.

11. Maltais F, Singh S, Donald AC, et al. Effects of a combination of umeclidinium/vilanterol on exercise endurance in patients with chronic obstructive pulmonary disease: two randomized, double-blind clinical trials. Ther Adv Respir Dis. 2014;8(6):169-181.

12. Watz H, Troosters T, Beeh KM, et al. ACTIVATE: the effect of aclidinium/formoterol on hyperinflation, exercise capacity, and physical activity in patients with COPD. Int J Chron Obstruct Pulm Dis. 2017; 12:2545-2558.

13. Watz H, Mailänder C, Baier M, Kirsten A. Effects of indacaterol/ glycopyrronium (QVA149) on lung hyperinflation and physical activity in patients with moderate to severe COPD: a randomised, placebocontrolled, crossover study (The MOVE Study). BMC Pulm Med. 2016; 16(1):95.

14. Ichinose M, Minakata Y, Motegi T, et al. Study design of VESUTO ${ }^{\circledR}$ : efficacy of tiotropium/olodaterol on lung hyperinflation, exercise capacity, and physical activity in Japanese patients with chronic obstructive pulmonary disease. Adv Ther. 2017;34(7):1622-1635.

15. Byrom B, Rowe DA. Measuring free-living physical activity in COPD patients: deriving methodology standards for clinical trials through a review of research studies. Contemp Clin Trials. 2016;47: 172-184.

16. Watz H, Pitta F, Rochester CL, et al. An official European Respiratory Society statement on physical activity in COPD. Eur Respir J. 2014; 44(6):1521-1537.
17. Camillo CA, Langer D, Osadnik CR, et al. Survival after pulmonary rehabilitation in patients with COPD: impact of functional exercise capacity and its changes. Int J Chron Obstruct Pulmon Dis. 2016;11: 2671-2679.

18. Andrianopoulos V, Wouters EF, Pinto-Plata VM, et al. Prognostic value of variables derived from the six-minute walk test in patients with COPD: results from the ECLIPSE study. Respir Med. 2015;109(9): 1138-1146.

19. Celli B, Tetzlaff K, Criner G, et al; COPD Biomarker Qualification Consortium. The 6-minute-walk distance test as a chronic obstructive pulmonary disease stratification tool. Insights from the COPD biomarker qualification consortium. Am J Respir Crit Care Med. 2016;194(12): 1483-1493.

20. Calzetta L, Ora J, Cavalli F, Rogliani P, O’Donnell DE, Cazzola M. Impact of LABA/LAMA combination on exercise endurance and lung hyperinflation in COPD: a pair-wise and network meta-analysis. Respir Med. 2017;129:189-198.

21. Casaburi R, Maltais F, Porszasz J, et al. Effects of tiotropium on hyperinflation and treadmill exercise tolerance in mild to moderate chronic obstructive pulmonary disease. Ann Am Thorac Soc. 2014;11(9): 1351-1361.

22. Puente-Maestu L, Palange P, Casaburi R, et al. Use of exercise testing in the evaluation of interventional efficacy: an official ERS statement. Eur Respir J. 2016;47(2):429-460.

23. Casaburi R, Kukafka D, Cooper CB, Witek TJ Jr, Kesten S. Improvement in exercise tolerance with the combination of tiotropium and pulmonary rehabilitation in patients with COPD. Chest. 2005;127(3):809-817.

24. Waatevik M, Johannessen A, Gomez Real F, et al. Oxygen desaturation in 6-min walk test is a risk factor for adverse outcomes in COPD. Eur Respir J. 2016;48(1):82-91.

25. Vaes AW, Garcia-Aymerich J, Marott JL, et al. Changes in physical activity and all-cause mortality in COPD. Eur Respir J. 2014;44(5): 1199-1209.

26. Waschki B, Kirsten A, Holz O, et al. Physical activity is the strongest predictor of all-cause mortality in patients with COPD: a prospective cohort study. Chest. 2011;140(2):331-342.

27. Global Strategy for the Diagnosis, Management and Prevention of COPD, Global Initiative for Chronic Obstructive Lung Disease (GOLD) 2017 [homepage on the Internet]. Available from: http://goldcopd.org. Accessed October 30, 2017.

28. Committee for the 4 th edition of the COPD guidelines of the Japanese Respiratory Society. [Guidelines for the diagnosis and treatment of COPD (chronic obstructive pulmonary disease)] 4th edition. Tokyo, Japan: The Japanese Respiratory Society; 2013. Japanese.

29. Mantoani LC, Rubio N, McKinstry B, MacNee W, Rabinovich RA. Interventions to modify physical activity in patients with COPD: a systematic review. Eur Respir J. 2016;48(1):69-81.

30. Mendoza L, Horta P, Espinoza J, et al. Pedometers to enhance physical activity in COPD: a randomised controlled trial. Eur Respir J. 2015; 45(2):347-354.

31. Pleguezuelos E, Pérez ME, Guirao L, et al. Improving physical activity in patients with COPD with urban walking circuits. Respir Med. 2013; 107(12):1948-1956. 


\section{Supplementary materials \\ Analysis groups}

The primary analysis was performed in the full analysis set, comprising all patients who had signed informed consent, were randomized, and had taken any dose of study medication, and had non-missing baseline data at Visit 2 and nonmissing post-dose baseline measurements of inspiratory capacity (IC) at rest for the primary endpoint.

The safety analysis was conducted in the analysis set that consisted of all treated patients.

\section{Determination of sample size}

For the primary endpoint of IC at rest after Week 6, results from the recent two Boehringer Ingelheim studies (data on file) suggested that the SD was $\sim 0.4 \mathrm{~L}$. However, a conservative $0.41 \mathrm{~L}$ was deemed more appropriate due to uncertain prediction of drop-outs during tests for physical activities. In addition, the IC at rest after Week 6 was estimated at $0.1 \mathrm{~L}$ for the difference between tiotropium/olodaterol and tiotropium. To detect a difference of $0.1 \mathrm{~L}$ with the SD of $0.41 \mathrm{~L}$ in the IC at rest between the two treatments with $90 \%$ power at the two-sided alpha of $0.05,180$ patients were required. Nquery Advisor nTerim ver.2.0 (MOT0-1, one-sample $t$-test) was used for the sample size calculation.

\section{Statistical analysis}

The primary analysis was conducted using mixed-effects model repeated measures including treatment and period as

Table SI Investigator, site, and IRB list

\begin{tabular}{|c|c|c|c|}
\hline Investigator name & Site name (location) & IRB (location) & Approval number (date) \\
\hline Hataji, Osamu & $\begin{array}{l}\text { Matsusaka City Hospital } \\
\text { (Matsusaka, Mie, Japan) }\end{array}$ & Same as on the left & $(22 \operatorname{Dec} 2015)^{a}$ \\
\hline Higashimoto, Yuji & $\begin{array}{l}\text { Kindai University Hospital } \\
\text { (Osakasayama, Osaka, Japan) }\end{array}$ & Same as on the left & $\begin{array}{l}1724 \\
(22 \operatorname{Dec} 2015)^{\mathrm{a}}\end{array}$ \\
\hline Kondoh, Yasuhiro & $\begin{array}{l}\text { Tosei General Hospital } \\
\text { (Seto, Aichi, Japan) }\end{array}$ & Same as on the left & $\begin{array}{l}\text { H27I I 04Ba679+BII } 744 \\
(24 \text { Nov 20I5) }\end{array}$ \\
\hline Suzuki, Masaru & $\begin{array}{l}\text { Hokkaido University Hospital } \\
\text { (Sapporo, Hokkaido, Japan) }\end{array}$ & Same as on the left & $\begin{array}{l}15066 \\
\text { (I5 Dec 20I5) }\end{array}$ \\
\hline Ohbayashi, Hiroyuki & $\begin{array}{l}\text { Tohno Chuo Clinic } \\
\text { (Mizunami, Gifu, Japan) }\end{array}$ & $\begin{array}{l}\text { Shinagawa East One Medical Clinic } \\
\text { (Minato-ku, Tokyo, Japan) }\end{array}$ & $(14 \mathrm{Dec} 2015)^{\mathrm{a}}$ \\
\hline Saito, Takefumi & $\begin{array}{l}\text { NHO Ibarakihigashi National Hospital } \\
\text { (Naka-gun, Ibaraki, Japan) }\end{array}$ & Same as on the left & $(18 \operatorname{Dec} 2015)^{a}$ \\
\hline Asai, Kazuhisa & $\begin{array}{l}\text { Osaka City University Hospital } \\
\text { (Osaka, Osaka, Japan) }\end{array}$ & Same as on the left & $(17 \mathrm{Dec} 2015)^{\mathrm{a}}$ \\
\hline Miura, Motohiko & $\begin{array}{l}\text { Japan Organization of Occupational Health and } \\
\text { Safety Tohoku Rosai Hospital } \\
\text { (Sendai, Miyagi, Japan) }\end{array}$ & Same as on the left & $\begin{array}{l}\text { I5AOI2a } \\
(17 \mathrm{Dec} 20 \mathrm{I5})\end{array}$ \\
\hline Miyao, Naoki & $\begin{array}{l}\text { Medical Corporation Kokankai Kokan Clinic } \\
\text { (Kawasaki, Kanagawa, Japan) }\end{array}$ & $\begin{array}{l}\text { Nihon Kokan Hospital } \\
\text { (Kawasaki, Kanagawa, Japan) }\end{array}$ & $(03 \mathrm{Dec} 2015)^{\mathrm{a}}$ \\
\hline Nagashima, Hirotaka & $\begin{array}{l}\text { Shinjuku Research Park Clinic } \\
\text { (Shinjuku-ku, Tokyo, Japan) }\end{array}$ & $\begin{array}{l}\text { Tokyo-Eki Center-building Clinic } \\
\text { (Chuo-ku, Tokyo, Japan) }\end{array}$ & $\begin{array}{l}427200-2015 I 211 \\
(I I \text { Dec 20I5) }\end{array}$ \\
\hline Sugiura, Hisatoshi & $\begin{array}{l}\text { Tohoku University Hospital } \\
\text { (Sendai, Miyagi, Japan) }\end{array}$ & Same as on the left & $\begin{array}{l}|5| 03 \mid \\
(2|\operatorname{Dec} 20| 5)\end{array}$ \\
\hline Harada, Toshiyuki & $\begin{array}{l}\text { Japan Community Health Care Organization } \\
\text { Hokkaido Hospital } \\
\text { (Sapporo, Hokkaido, Japan) }\end{array}$ & Same as on the left & $(10 \mathrm{Dec} 2015)^{\mathrm{a}}$ \\
\hline Hiramatsu, Tetsuo & $\begin{array}{l}\text { Hiramatsu Internal and Respiratory Medicine Clinic } \\
\text { (Komaki, Aichi, Japan) }\end{array}$ & $\begin{array}{l}\text { Shinagawa East One Medical Clinic } \\
\text { (Minato-ku, Tokyo, Japan) }\end{array}$ & $(14 \operatorname{Dec} 2015)^{\mathrm{a}}$ \\
\hline Tsuchiya, Michiko & $\begin{array}{l}\text { Rakuwakai Otowa Hospital } \\
\text { (Kyoto, Kyoto, Japan) }\end{array}$ & Same as on the left & $\begin{array}{l}1509 \\
\text { (II Dec 2015) }\end{array}$ \\
\hline Kinoshita, Takashi & $\begin{array}{l}\text { Kurume University Hospital } \\
\text { (Kurume, Fukuoka, Japan) }\end{array}$ & Same as on the left & $\begin{array}{l}215039 \\
(18 \mathrm{Feb} 2016)\end{array}$ \\
\hline Tsuda, Tohru & $\begin{array}{l}\text { Kirigaoka Tsuda Hospital (Kitakyushu, } \\
\text { Fukuoka, Japan) }\end{array}$ & Same as on the left & $($ I5 Dec 20I5)a \\
\hline Muro, Shigeo & $\begin{array}{l}\text { Kyoto University Hospital } \\
\text { (Kyoto, Kyoto, Japan) }\end{array}$ & Same as on the left & $\begin{array}{l}1749 \\
(13 \mathrm{Jan} 2016)\end{array}$ \\
\hline Utsumi, Yu & $\begin{array}{l}\text { Iwate Medical University Hospital } \\
\text { (Morioka, Iwate, Japan) }\end{array}$ & Same as on the left & $\begin{array}{l}215041 \\
(16 \operatorname{Dec} 2015)\end{array}$ \\
\hline
\end{tabular}


Table SI (Continued)

\begin{tabular}{|c|c|c|c|}
\hline Investigator name & Site name (location) & IRB (location) & Approval number (date) \\
\hline Ichiwata, Toshio & $\begin{array}{l}\text { Tokyo Medical University Hachioji Medical Center } \\
\text { (Hachioji, Tokyo, Japan) }\end{array}$ & Same as on the left & $(29 \text { Jan } 2016)^{a}$ \\
\hline Kaneko, Masahiro & $\begin{array}{l}\text { Kobe City Hospital Organization Kobe City } \\
\text { Medical Center West Hospital } \\
\text { (Kobe, Hyogo, Japan) }\end{array}$ & Same as on the left & $(14 \mathrm{Dec} 2015)^{\mathrm{a}}$ \\
\hline Samukawa, Takuya & $\begin{array}{l}\text { Kagoshima University Hospital and Dental Hospital } \\
\text { (Kagoshima, Kagoshima, Japan) }\end{array}$ & Same as on the left & $\begin{array}{l}15012 \\
(16 \mathrm{Dec} 2015)\end{array}$ \\
\hline Motegi, Takashi & $\begin{array}{l}\text { Respiratory Care Clinic, Nippon Medical School } \\
\text { (Chiyoda-ku, Tokyo, Japan) }\end{array}$ & $\begin{array}{l}\text { Nihon Medical School } \\
\text { (Bunkyo-ku, Tokyo, Japan) }\end{array}$ & $\begin{array}{l}127024 \\
(08 \text { Jan 2016) }\end{array}$ \\
\hline Minakata, Yoshiaki & $\begin{array}{l}\text { NHO Wakayama Hospital } \\
\text { (Hidaka-gun, Wakayama, Japan) }\end{array}$ & Same as on the left & $\begin{array}{l}201502 \\
(1 I \text { Dec 20I5) }\end{array}$ \\
\hline Fuke, Satoshi & $\begin{array}{l}\text { KKR Sapporo Medical Center } \\
\text { (Sapporo, Hokkaido, Japan) }\end{array}$ & Same as on the left & $(04 J a n 2016)^{a}$ \\
\hline Kato, Motokazu & $\begin{array}{l}\text { Kishiwada City Hospital } \\
\text { (Kishiwada, Osaka, Japan) }\end{array}$ & Same as on the left & $(19 J \operatorname{Jan} 2016)^{\mathrm{a}}$ \\
\hline Gon, Yasuhiro & $\begin{array}{l}\text { Nihon University Itabashi Hospital } \\
\text { (Itabashi-ku, Tokyo, Japan) }\end{array}$ & Same as on the left & $\begin{array}{l}27 \mid 2-1448 \\
(18 \text { Dec 20I5) }\end{array}$ \\
\hline Nagai, Atsushi & $\begin{array}{l}\text { Shin-yurigaoka General Hospital } \\
\text { (Kawasaki, Kanagawa, Japan) }\end{array}$ & $\begin{array}{l}\text { Koyasu Neurosurgical Clinic } \\
\text { (Yokohama, Kanagawa, Japan) }\end{array}$ & $(25$ Jan 2016) \\
\hline Harada, Hiromasa & $\begin{array}{l}\text { Yao Tokushukai General Hospital } \\
\text { (Yao, Osaka, Japan) }\end{array}$ & $\begin{array}{l}\text { Tokushukai Group IRB } \\
\text { (Chiyoda-ku, Tokyo, Japan) }\end{array}$ & $\begin{array}{l}004-15-02 \\
(18 \text { Dec 2015) }\end{array}$ \\
\hline Tomii, Keisuke & $\begin{array}{l}\text { Kobe City Medical Center General Hospital } \\
\text { (Kobe, Hyogo, Japan) }\end{array}$ & Same as on the left & $\begin{array}{l}15-25 \\
\text { (15 Dec 20I5) }\end{array}$ \\
\hline Harada, Yasuko & $\begin{array}{l}\text { Nishi Fukuoka Hospital } \\
\text { (Fukuoka, Fukuoka, Japan) }\end{array}$ & Same as on the left & $(17 \mathrm{Dec} 2015)^{\mathrm{a}}$ \\
\hline Saito, Masahiko & $\begin{array}{l}\text { Uji Tokushukai Medical Center } \\
\text { (Uji, Ktoto, Japan) }\end{array}$ & $\begin{array}{l}\text { Tokushukai Group IRB } \\
\text { (Chiyoda-ku, Tokyo, Japan) }\end{array}$ & $\begin{array}{l}007-15-12 \\
(18 \operatorname{Dec} 2015)\end{array}$ \\
\hline Sato, Tadashi & $\begin{array}{l}\text { Juntendo University Hospital } \\
\text { (Bunkyo-ku, Tokyo, Japan) }\end{array}$ & Same as on the left & $\begin{array}{l}2015-022 \\
(25 \text { Dec 2015) }\end{array}$ \\
\hline Sagara, Hironori & $\begin{array}{l}\text { Showa University Hospital } \\
\text { (Shinagawa-ku, Tokyo, Japan) }\end{array}$ & Same as on the left & $\begin{array}{l}1511022(201501) \\
(08 \text { Jan 2016) }\end{array}$ \\
\hline Nakamura, Hiroyuki & $\begin{array}{l}\text { Sakaide City Hospital } \\
\text { (Sakaide, Kagawa, Japan) }\end{array}$ & Same as on the left & $(22 \operatorname{Jan} 2016)^{\mathrm{a}}$ \\
\hline Shikama, Yusuke & $\begin{array}{l}\text { Showa University Fujigaoka Hospital } \\
\text { (Yokohama, Kanagawa, Japan) }\end{array}$ & Same as on the left & $\begin{array}{l}2015100 \\
(08 \text { Jan 2016) }\end{array}$ \\
\hline Osaki, Shinichi & $\begin{array}{l}\text { Osaki Internal and Respiratory Clinic } \\
\text { (Kitakyushu, Fukuoka, Japan) }\end{array}$ & $\begin{array}{l}\text { Hoshikuma Hihuka Allergy Clinic } \\
\text { (Fukuoka, Fukuoka, Japan) }\end{array}$ & $(22 \operatorname{Dec} 2015)^{\mathrm{a}}$ \\
\hline Nishimura, Koichi & $\begin{array}{l}\text { National Center for Geriatrics and Gerontology } \\
\text { (Obu, Aichi, Japan) }\end{array}$ & Same as on the left & $\begin{array}{l}15108 \\
(01 \text { Feb 2016) }\end{array}$ \\
\hline Koba, Hiroyuki & $\begin{array}{l}\text { Teine Keijinkai Clinic } \\
\text { (Sapporo, Hokkaodo, Japan) }\end{array}$ & Same as on the left & $\begin{array}{l}\text { TKC20I6-0I } \\
\text { (I2 Feb 20I6) }\end{array}$ \\
\hline Miki, Keisuke & $\begin{array}{l}\text { NHO Toneyama National Hospital } \\
\text { (Toyonaka, Osaka, Japan) }\end{array}$ & Same as on the left & $\begin{array}{l}27-52 \\
(29 \text { Feb 2016) }\end{array}$ \\
\hline Mizobe, Yuriko & $\begin{array}{l}\text { Nihonbashi Sakura Clinic } \\
\text { (Chuo-ku, Tokyo, Japan) }\end{array}$ & Same as on the left & $(29 J \text { an } 2016)^{a}$ \\
\hline Onari, Yojiro & $\begin{array}{l}\text { Mazda Hospital } \\
\text { (Aki-gun, Hiroshima, Japan) }\end{array}$ & $\begin{array}{l}\text { Koyasu Neurosurgical Clinic } \\
\text { (Yokohama, Kanagawa, Japan) }\end{array}$ & $\left(29\right.$ Aug 2016) ${ }^{a}$ \\
\hline Hayakawa, Hiroshi & $\begin{array}{l}\text { NHO Tenryu Hospital } \\
\text { (Hamamatsu, Shizuoka, Japan) }\end{array}$ & Same as on the left & $\left(14\right.$ Sept 2016) ${ }^{a}$ \\
\hline Kawamura, Tetsuji & $\begin{array}{l}\text { NHO Himeji Medical Center } \\
\text { (Himeji, Hyogo, Japan) }\end{array}$ & Same as on the left & $\begin{array}{l}321 \\
(07 \text { Oct 2016) }\end{array}$ \\
\hline Isobe, Takeshi & $\begin{array}{l}\text { Shimane University Hospital } \\
\text { (Izumo, Shimane, Japan) }\end{array}$ & Same as on the left & $\begin{array}{l}28-8 \\
\text { (15 Sept 2016) }\end{array}$ \\
\hline
\end{tabular}

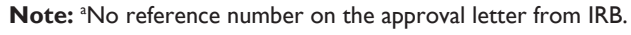

Abbreviation: IRB, institutional review board. 
Table S2 Treatment difference between tiotropium/olodaterol and tiotropium by GOLD stage subgroup

\begin{tabular}{|c|c|c|c|c|c|c|c|}
\hline & \multirow[t]{2}{*}{ Treatment } & \multirow[t]{2}{*}{$\mathbf{n}$} & \multirow{2}{*}{$\begin{array}{l}\text { Adjusted } \\
\text { mean (SE) } \\
6 \mathrm{MWD}^{\mathrm{a}}\end{array}$} & \multirow{2}{*}{$\begin{array}{l}\text { Adjusted mean } \\
\text { change from baseline } \\
(\mathrm{SE}) \text { in } 6 \mathrm{MWD}^{\mathrm{a}}\end{array}$} & \multicolumn{3}{|c|}{ Comparison vs T $5 \mu \mathrm{g}$} \\
\hline & & & & & $\begin{array}{l}\text { Adjusted mean } \\
\text { of difference (SE) }\end{array}$ & $95 \% \mathrm{Cl}$ & $p$-value \\
\hline \multirow[t]{2}{*}{ GOLD II } & T $5 \mu \mathrm{g}$ & 97 & $326.4(6.7)$ & $11.7(6.7)$ & $-5.4(6.9)$ & $(-19.0,8.2)$ & 0.4349 \\
\hline & $\mathrm{T} / \mathrm{O} 5 / 5 \mu \mathrm{g}$ & 96 & $321.0(6.7)$ & $6.3(6.7)$ & & & \\
\hline \multirow[t]{2}{*}{ GOLD III } & T $5 \mu \mathrm{g}$ & 65 & $294.4(9.3)$ & $15.7(9.3)$ & $16.9(9.2)$ & $(-1.5,35.3)$ & 0.0714 \\
\hline & $\mathrm{T} / \mathrm{O} 5 / 5 \mu \mathrm{g}$ & 66 & $311.3(9.3)$ & $32.6(9.3)$ & & & \\
\hline \multirow[t]{2}{*}{ GOLD IV } & T $5 \mu \mathrm{g}$ & 16 & $239.4(16.0)$ & $3.8(16.0)$ & $21.2(15.9)$ & $(-13.0,55.4)$ & 0.2048 \\
\hline & $\mathrm{T} / \mathrm{O} 5 / 5 \mu \mathrm{g}$ & 16 & $260.6(16.0)$ & $24.9(16.0)$ & & & \\
\hline
\end{tabular}

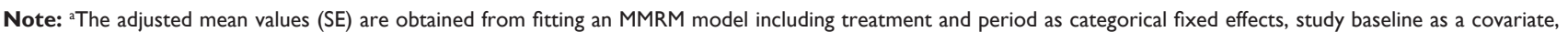
and patient as a random effect.

Abbreviations: 6MWD, 6-min walk distance; GOLD, Global Initiative for Chronic Obstructive Lung Disease; MMRM, mixed-effects model repeated measures; O, olodaterol; SE, standard error; T, tiotropium; T/O, tiotropium/olodaterol.

categorical fixed effects, study baseline as a covariate, and patient as a random effect. Compound symmetry was used as a covariance structure for within-patient variation. The SAS procedure MIXED was used, involving the restricted maximum likelihood estimation and the Kenward-Roger approximation for denominator degrees of freedom. Adjusted mean values as well as treatment contrasts were presented together with the $95 \%$ CIs and $p$-values.

\section{Concomitant diagnoses}

Of the total number of patients in the study, 174/184 (94.6\%) had concomitant diagnoses and $>50 \%$ had vascular disorders. Metabolic and nutritional disorders (46.2\%), gastrointestinal disorders (31.0\%), and cardiac disorders (17.4\%) were also commonly reported.

\section{The 6-min walk distance (6MWD)}

The 6-min walk test was performed according to the methodology described by American Thoracic Society guidelines.
The criterion of the $6 \mathrm{MWD}<400 \mathrm{~m}$ is referred to in studies that evaluated the combination therapy of tiotropium and formoterol compared to tiotropium and the ECLIPSE study which considered the relation of 6MWD with survival rate.

\section{Physical activity}

As a secondary endpoint, physical activity was compared between treatments. The adjusted mean values of average steps per day, average daily activity durations of $\geq 4, \geq 3$, and $\geq 2$ metabolic equivalents (METs), and average daily active strength in the 2 weeks prior to Week 6 were similar between the treatments. The treatment difference was 9.5 (95\% CI: -155.7 steps, 174.7 steps; $p=0.9098)$ steps/day for the average number of steps; $-0.3 \mathrm{~min}(95 \% \mathrm{CI}:-1.2 \mathrm{~min}$, $0.6 \mathrm{~min} ; p=0.5338$ ), $0.9 \mathrm{~min}$ ( $95 \% \mathrm{CI}$ : $-1.0 \mathrm{~min}, 2.9 \mathrm{~min}$; $p=0.3524)$ and $2.3 \mathrm{~min}(95 \% \mathrm{CI}:-3.0 \mathrm{~min}, 7.5 \mathrm{~min} ; p=0.3949)$; $2.4 \mathrm{~min}$ (95\% CI: $-4.6 \mathrm{~min}, 9.4 \mathrm{~min}$ ) for average daily duration $\geq 4$ METs, $\geq 3$ METs, $\geq 2$ METs; and average daily active strength (METs min) of $\geq 3$ METs, respectively.

\section{Publish your work in this journal}

The International Journal of COPD is an international, peer-reviewed journal of therapeutics and pharmacology focusing on concise rapid reporting of clinical studies and reviews in COPD. Special focus is given to the pathophysiological processes underlying the disease, intervention programs, patient focused education, and self management protocols.

\section{Dovepress}

This journal is indexed on PubMed Central, MedLine and CAS. The manuscript management system is completely online and includes a very quick and fair peer-review system, which is all easy to use. Visit http://www.dovepress.com/testimonials.php to read real quotes from published authors. 